\title{
Steady State Analysis for Power System of HSR with Active Transformer
}

\author{
Wook-Won Kim*, Hyung-Chul Kim**, Seung-Kwon Shin** and Jin-O Kim ${ }^{\dagger}$
}

\begin{abstract}
In this paper, new electric railway feeding system which has active transformer is modeled for evaluating the steady state analysis using PSCAD/EMTDC. Equivalent models including power supply, feeder, train and transformers are proposed for simplifying the model of the feeding system in high speed electric railway. In case study, simulation results applied to proposed model are compared with the conventional and new systems through the catenary voltage, three-phase voltage of PCC (Point of Common Coupling) and the efficiency of regenerative braking energy.
\end{abstract}

Keywords: Active transformer, SCOTT Transformer, Regenerative braking energy, Equivalent model, PSCAD/EMTDC Simulation

\section{Introduction}

The electric railway has been considered as the best alternative to the resolution of future traffic problems since it is safe, rapid and eco-friendly. In recent years, due to the increased passengers, the number of high-speed trains is also expected to increase, and the existing electric railway system could be adversely affected by the increased train loads. In case the intensive train loads is concentrated on phase of SCOTT Transformer and AT (Auto Transformer) in the conventional power feeding system, several drawbacks are brought such as unbalanced voltage and current, in addition significant voltage drop at catenary. In the high-speed rail (HSR) built in recent years, AT is applied to the power feeding system with a single-phase power supplied via a SCOTT Transformer to prevent an unbalance in the three phases. However, in these systems, the parallel feeding is difficult to be adopted in the conventional system due to the phase difference between the SCOTT Transformers and sectioning post (SP), and moreover, the existence of SP makes it unable to recover the regenerative braking energy due to the disconnected power feeding line by SP. Also, the increased load causes the voltage drop and power quality problems due to the inherent characteristics in SCOTT Transformer and AT as mentioned above. In order to prevent these problems such as unbalance, voltage drop and power quality, it has been proposed to install the compensation devices such as $\mathrm{AC}$ boost chopper, SPC (static power conditioner), SVC (Static VAR Compensator) and STATCOM [1-8]. However, these devices makes additional harmonic resonance problem in

$\dagger$ Corresponding Author: Dept. of Electrical Engineering, Hanyang University, Korea. (jokim@hanyang.ac.kr)

* Dept. of Electrical Engineering, Hanyang University, Korea. (neocruser@hanyang.ac.kr)

** Dept. Smart Station Research Team, Metropolitan Transportation Reseach Center, Korea. (\{hckim, skshin\}@krri.re.kr)

Received: April 15, 2015; Accepted: October 26, 2015 the system and are not able to solve the problems fundamentally. Recently, the back-to-back converter technologies have been applied to renewable energy system which generates single-phase power and needs to be converted to three-phase from single-phase in order to connect to the grid [9-13]. This technology could be applied to the railway power feeding system to prevent the unbalance of the three-phase and enabling to reuse regenerative braking energy. Therefore, it is advantageous to the conventional system that replacing the SCOTT Transformer with back-to-back converter.

In this paper, an equivalent model is proposed for new high speed electric railway power feeding system with back-to-back converter, which is called by Active Transformer, and is evaluated for the steady state analysis using PSCAD/EMTDC. In the case study, simulation results using proposed model are compared with the conventional and new systems through the catenary voltage, three-phase voltage of PCC (Point of Common Coupling) and the efficiency of regenerative braking energy.

\section{System Descriptions}

\subsection{Conventional electric railway system}

The conventional power system for HSR (High Speed Railway) in Korea consists of 10 substation (SS), 9 sectioning posts (SP) and 26 sub-sectioning post (SSP) or parallel post (PP) as shown in Fig. 1. The SP is installed between SSs and it is always open at normal for protecting the system stability because of phase difference in voltages supplied from both sides of SS. Due to the normal open SP, there exist dead sections at SP and the train moves without power feeding at this section (coasting). The large unbalanced current is produced by the sudden changes in load when train is entering or exiting into the dead section. 


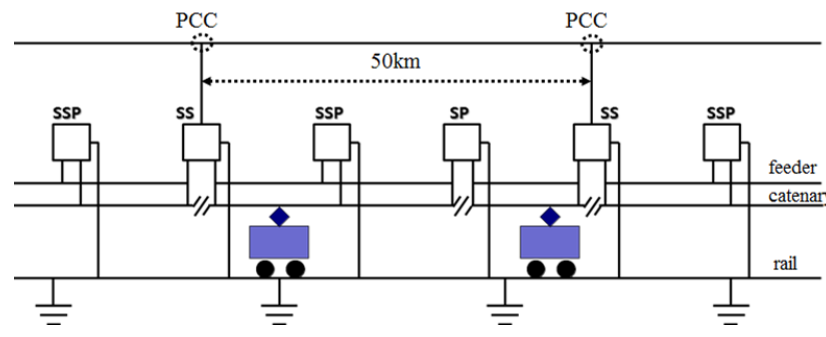

Fig. 1. Electric railway system configuration

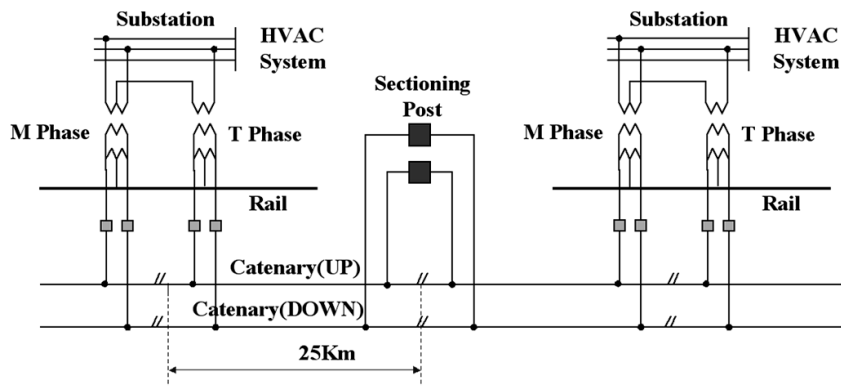

Fig. 2. Typical feeding configuration of AC HSR system

This causes 3 phase unbalance voltage of the PCC (Point of Common Coupling) which denotes the point at the primary side of SS. In addition, it is difficult to use regenerative braking energy because the circuit is separated by SP[14-16]. When the fault is occurred at one of SS, another SS performs the extended power feeding, which causes voltage drop too much at the opposite side of SS. Parallel power feeding means the power feeding from both sides of SSs is available only if the difference phase angle is not exceeded $3 \%$. However, parallel power feeding is not implemented generally in the conventional system since the difference of phase angle is usually over $3 \%$.

SCOTT Transformers are installed at every SS $(50 \mathrm{~km})$ and transform 3-phase $154 \mathrm{kV}$ into two single phases $55 \mathrm{kV}$ which are called M-phase (Main) and T-phase (Teaser). Each voltage $(55 \mathrm{Kv})$ from $\mathrm{M}$ and $\mathrm{T}$ phase is divided into two voltages $(27.5 \mathrm{kV} / \mathrm{AC}$ ) by AT (Auto Transformer) and supplied to the catenary and feeder as well. Typical feeding configuration of AC HSR system is described in Fig. 2[17].

\subsection{Electric railway system with Active Transformer}

As mentioned above, the conventional power feeding system with SCOTT Transformer and AT has several drawbacks such as unbalanced voltage and current due to the dead section at SP, significant voltage drop at catenary in case of extended feeding, and no regenerative braking due to the separation of catenary and feeder in pieces by SP and SS. Therefore, the need for new system is recognized, which replaces the conventional system with step-down transformers and back-to-back converter which is called as "Active Transformer". As shown in Fig. 3, transformer 1 converts 3-phase AC $154 \mathrm{kV}$ to $55 \mathrm{kV}$ as same as the SCOTT

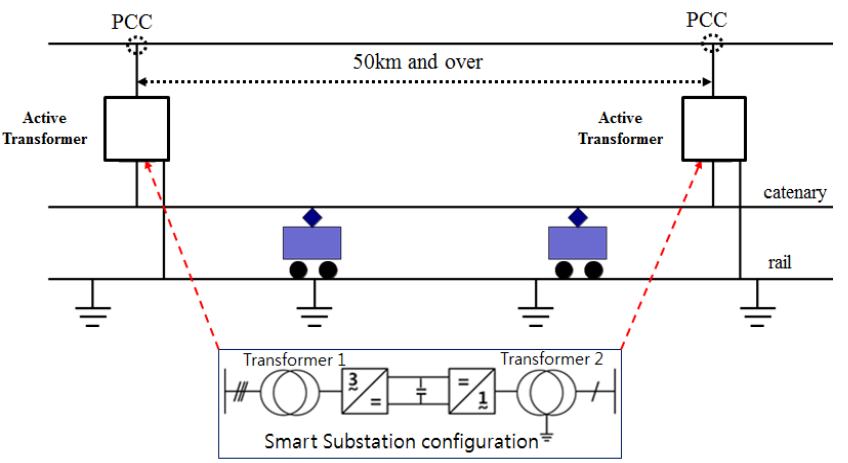

Fig. 3. Electric railway system configuration with active transformer

Transformer in conventional system. This stepped-down AC voltage is rectified to $\mathrm{DC} 75 \mathrm{kV}$ and inverted to single phase AC $55 \mathrm{kV}$ through back-to-back converter. Finally, it is stepped down again to $\mathrm{AC} 27.5 \mathrm{kV}$ by transformer 2 and is fed into railway power system. In this system, there are no dead sections by SS and SP, and Active Transformer enables to control the system frequency, voltage, phase angle and reactive power by controlling IGBT switching, therefore all drawbacks in conventional system could be disappeared in one stroke.

\section{System Modeling}

In case that Active Transformer introduced in this paper is replaced with SCOTT Transformer in the conventional power feeding system, it is necessary to compare the system performance between the conventional and new systems. To prove it, the HSR system is modeled by PSCAD/EMTDC for analyzing steady state such as voltage unbalance, voltage drop, and energy efficiency by regenerative braking for both cases of constant and variable train loads which mean constant acceleration all the time and repeated acceleration and deceleration by turns according to the driving mode, respectively.

\subsection{Transmission line and power supply}

Transmission lines before PCC are owned by utility and usually are composed of underground cables rather than overhead lines. Fig. 4 shows the PSCAD model of typical underground transmission line for three-phase $154 \mathrm{kV}$ and is connected to SCOTT Transformers in the substation after PCC, which is owned by Railway Company. The details of SCOTT connection diagram is shown in Fig. 5.

\subsection{Catenary, Feeder and rail}

Equivalent model of catenary and feeding line can be established by using the typical feeding configuration shown in Fig. 4, where substations at the both ends of line 


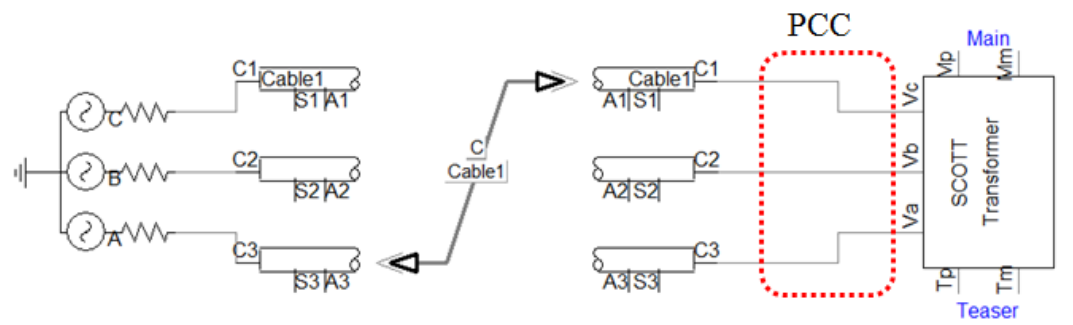

Fig. 4. Power supply and transmission

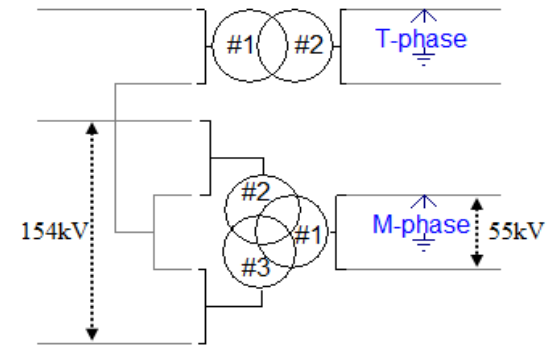

Fig. 5. SCOTT Transformer connection diagram

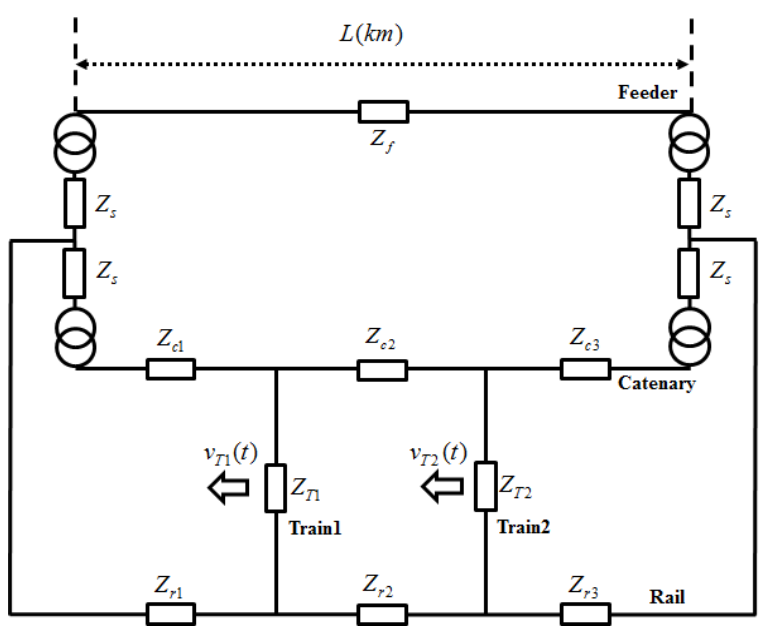

Fig. 6. Equivalent model of catenary and feeding line.

denote ATs with the distance between them of $\mathrm{L} \mathrm{km}$, typically $50 \mathrm{~km}$. As shown in equivalent model at Fig. 6, AT is tapped at the mid-point to divide into two reduced voltages, and one is connected to catenary and another one is connected to feeder. The neutral point of tapped AT is connected to the rail. $Z_{s}$ is one half of the impedance of tapped AT, and $Z_{c}, Z_{r}$ and $Z_{f}$ are the line impedances in the catenary, rail and return feeder, respectively. Catenary and rail impedances are subdivided into several intervals depending upon train positions and the number of trains in the same power-feeding section, and the amount of impedance in each interval is continually changed by moving train.

Let $v_{T 1}(t)$ and $v_{T 2}(t)$ be the speed of the trains and the second train is assumed to enter the same power-feeding section after alpha seconds later, then position of each train can be represented by (1), and subdivided catenary and rail

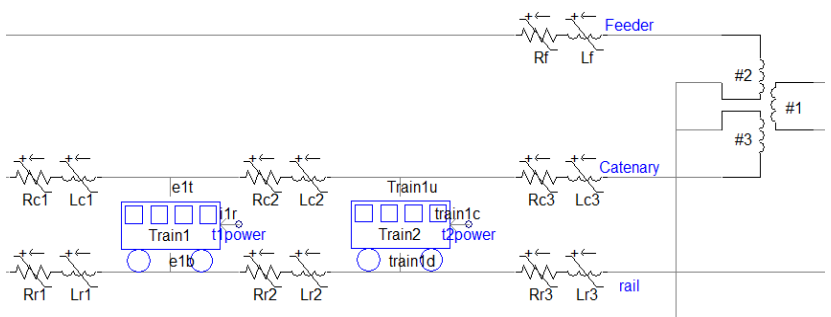

Fig. 7. PSCAD model of AT and power feeding section

impedances by the train position can be calculated using (2) and (3), respectively.

$$
\begin{gathered}
L_{T 1}(t)=\int_{t=0}^{T} v_{T 1}(t+\alpha) \\
L_{T 2}(t)=\int_{t=0}^{T} v_{T 2}(t) \\
Z_{c 1}(\mathrm{t})=\frac{L-L_{T 1}(\mathrm{t})}{L} Z_{C} \\
Z_{c 2}(\mathrm{t})=\frac{L_{T 1}(\mathrm{t})-L_{T 2}(\mathrm{t})}{L} Z_{C} \\
Z_{c 3}(\mathrm{t})=\frac{L_{T 2}(\mathrm{t})}{L} Z_{C} \\
Z_{r 1}(\mathrm{t})=\frac{L-L_{T 1}(\mathrm{t})}{L} Z_{R} \\
Z_{r 2}(\mathrm{t})=\frac{L_{T 1}(\mathrm{t})-L_{T 2}(\mathrm{t})}{L} Z_{R} \\
Z_{r 3}(\mathrm{t})=\frac{L_{T 2}(\mathrm{t})}{L} Z_{R}
\end{gathered}
$$

Eqs (1), (2) and (3) are applied to PSCAD model for evaluating the time-varying impedances of $R$ and $L$. Fig. 7 shows the PSCAD model of AT and power feeding section including the time varying resistance and inductance, which is implemented practically for the equivalent model shown in Fig. 6 in detail.

\subsection{Train load}

Typically train is driven under coasting without any power consumption after being accelerated up to maximum speed. It is reaccelerated for maintaining speed and then decelerated to stop at destination. The characteristic of train speed change between stations is described in Fig. 8. 
Train load is simply modeled with impedance and controlled current source as shown in Fig. 9 Impedance is inversely proportional to the acceleration of the train as shown in (4), and the switch BRK in Fig. 9 is closed when accelerated.

$$
R_{T}=\frac{V_{C A}{ }^{2}}{P_{T}^{\text {rate }}} \times \frac{\max A c c}{d v_{T}(t) / d t} \text { for Acceleration }
$$

where $R_{T}, V_{C A}$ and $P_{T}^{\text {rate }}$ are resistance of train, catenary voltage and rate power of train, respectively

When decelerated, two cases are considered; generative and regenerative braking. The former means the braking energy is lost by heat through the braking resistance, and for the latter case, regenerative braking energy is supplied to another train in the same section. The 'train control' in Fig. 8 denotes the control signal to determine the amount of regenerative braking energy. The switch scheme is summarized in Table 1 according to the driving modes.

\subsection{Active transformer}

Active transformer is a kind of back-to-back converter to

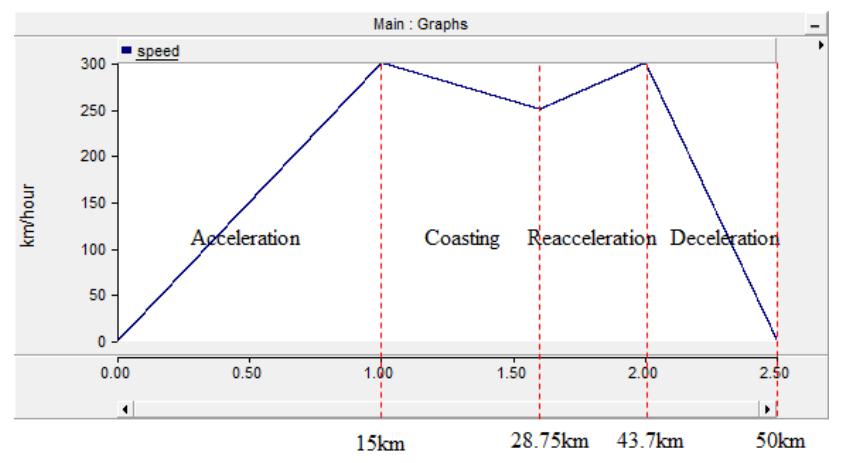

Fig. 8. Speed characteristic of train

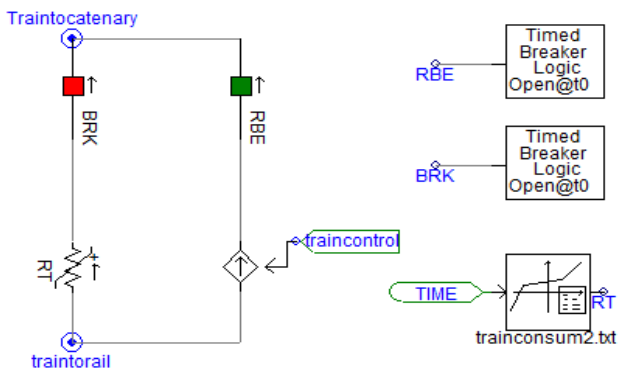

Fig. 9. Train model including regenerative braking

Table 1. Switch scheme of train

\begin{tabular}{c|c|c|c}
\hline \multirow{2}{*}{ Driving mode } & \multicolumn{2}{c}{ Switching state } \\
\cline { 2 - 3 } & BRK & RBE \\
\hline \multicolumn{2}{c}{ Acceleration } & ON & OFF \\
\hline \multirow{2}{*}{ Deceleration } & Regenerative braking & OFF & ON \\
\cline { 2 - 4 } & Generative braking & OFF & OFF \\
\hline \multicolumn{2}{c}{ Coasting } & OFF & OFF \\
\hline
\end{tabular}

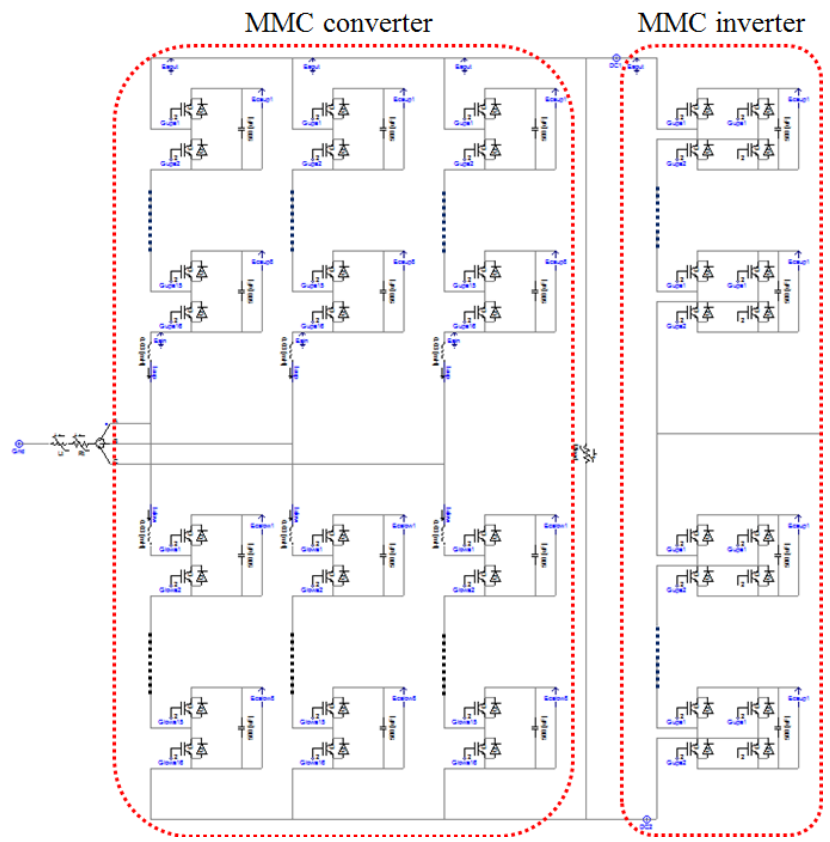

Fig. 10. MMC model by PSCAD/EMTDC

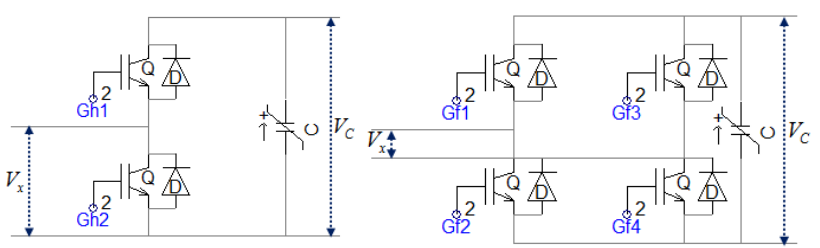

(a)

(b)

Fig. 11. (a) Sub-module of Half-bridge and (b) Full-bridge

convert 3-phase AC from a single phase AC, and is divided by rectifier and inverter sides with MMC (Modular Multilevel Converter) which includes $N$ sub-modules as shown in Fig. 10.

Fig. 11 shows the detailed PSCAD models for half and full-bridge sub-modules corresponding to rectifier and inverter sides.

Using the simplified model [18, 19], a sub-module can be represented by resistors and capacitor voltage source as shown in Fig. 12. Since the parallel connection of an IGBT and a diode acts as a bidirectional switch, only one out of two IGBTs is conducting at a given instance with the values of $R_{1}$ or $R_{2}$. Capacitor resistance $R_{C}$ varies depending upon the switching mode, and is simply calculated by using the values of capacitor current and voltage $\left(V_{C e q}\right)$ at the instant of simulation.

Then the equivalent resistance of a sub-module can be represented by (5)

$$
R_{e q}=R_{2}\left[1-\frac{R_{2}}{R_{1}+R_{2}+R_{C}}\right]
$$

Terminal voltage $\left(V_{e q}\right)$ of a sub-module is obtained by 
superposition of two voltages; one is the voltage due to the external current $\left(I_{S M}\right)$ and another is the contribution from the internal capacitor voltage, given by (6).

$$
V_{e q}=R_{e q} I_{S M}+\frac{R_{2}}{R_{1}+R_{2}+R_{C}} V_{C e q}
$$

This $N$ sub-modules are stacked to construct MMC and create output voltage by summing up the voltage of each sub-module.

\section{Case Study}

Fig. 13 shows the overall PSCAD model of conventional HSR power supply system based on the electric railway system configuration as appeared on Fig. 1. For the new system, SP is not required anymore due to introduction of Active Transformer, and SCOTT Transformer and AT are replaced by MMC and step up and down transformers appeared in Fig. 2 and Fig. 10, respectively. Furthermore, SS can be installed widely than existing distance $(50 \mathrm{~km})$ since the parallel feeding is possible from the Active Transformers installed at both ends. However, in this paper, in order to make the comparison, it is assumed that SSs have the same distance $(50 \mathrm{~km})$ of both systems.

Data for all components are given in Table 2 to simulate

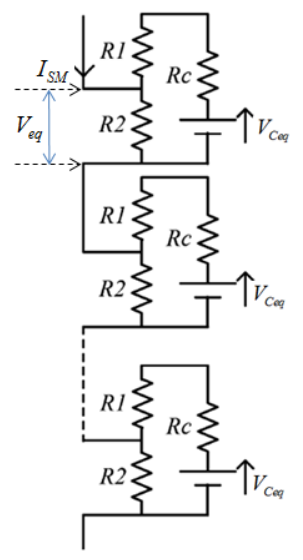

Fig. 12. Equivalent model of MMC the steady state of catenary voltage, three-phase voltage at $\mathrm{PCC}$, and regenerative braking energy according to the distance from substation. .

\subsection{Catenary voltage}

In order to consider the worst case of voltage drop, it is assumed at first that the train is operated with constant rated power at all positions to measure the catenary voltages according to the moving train position.

Fig. 14 shows the change of catenary voltage in conventional and new systems where the train load has constant rated power. When the train moves from a SS to the other SS, it can be observed that the catenary voltage $(27.5 \mathrm{kV})$ at the beginning SS drops to near the $24.8 \mathrm{kV}$ at the end of another SS, and the drop rate is $90.2 \%$ which barely meets the minimum voltage criteria of IEC. When $\mathrm{SP}$ is closed due to failure of transformer and parallel power feeding is required, voltage is decreased more and more where trains moves to opposite side of transformer.

Table 2. Data for simulation

\begin{tabular}{|c|c|c|c|}
\hline \multirow{2}{*}{ Main feeder } & Rated voltage & \multicolumn{2}{|c|}{$154 \mathrm{kV}$} \\
\hline & Impedance & \multicolumn{2}{|c|}{$0.3876+\mathrm{j} 1.7278$} \\
\hline \multirow{3}{*}{$\begin{array}{c}\text { SCOTT } \\
\text { Transformer }\end{array}$} & Rated capacity & \multicolumn{2}{|c|}{$90 \mathrm{MVA}$} \\
\hline & Rated voltage & \multicolumn{2}{|c|}{$154 / 55 \mathrm{kV}$} \\
\hline & Impedance & \multicolumn{2}{|c|}{$12.5 \%$} \\
\hline \multirow{4}{*}{ Catenary } & Catenary & \multicolumn{2}{|c|}{$0.1940+\mathrm{j} 0.7310[\Omega / \mathrm{km}]$} \\
\hline & Feeder & \multicolumn{2}{|c|}{$0.1220+\mathrm{j} 0.5870[\Omega / \mathrm{km}]$} \\
\hline & Rail & \multicolumn{2}{|c|}{$0.0990+\mathrm{j} 0.4670[\Omega / \mathrm{km}]$} \\
\hline & Length & \multicolumn{2}{|c|}{$50 \mathrm{~km}$} \\
\hline \multirow{4}{*}{ AT } & Rated capacity & \multicolumn{2}{|c|}{ 10MVA } \\
\hline & Rated voltage & \multicolumn{2}{|c|}{$55 / 27.5 \mathrm{kV}$} \\
\hline & Impedance & \multicolumn{2}{|c|}{$8 \%$} \\
\hline & Spacing & \multicolumn{2}{|c|}{$10 \mathrm{~km}$} \\
\hline \multirow{4}{*}{ Train } & Rated capacity & \multicolumn{2}{|c|}{$14[\mathrm{MW}]$} \\
\hline & Rated voltage & \multicolumn{2}{|c|}{$27.5 \mathrm{kV}$} \\
\hline & Power factor & \multicolumn{2}{|c|}{1.0} \\
\hline & Impedance & \multicolumn{2}{|c|}{50.42} \\
\hline \multirow{6}{*}{$\begin{array}{c}\text { Active } \\
\text { transformer }\end{array}$} & & Rectifier & inverter \\
\hline & Nominal power & $30 \mathrm{MVA}$ & $30 \mathrm{MVA}$ \\
\hline & DC voltage & $75 \mathrm{kV}$ & $75 \mathrm{kV}$ \\
\hline & Resistance & $3.6 \mathrm{k} \Omega$ & $3.6 \mathrm{k} \Omega$ \\
\hline & Switching Hz & $1.2 \mathrm{kHz}$ & $1.2 \mathrm{kHz}$ \\
\hline & Sub-module C & $560 \mu \mathrm{F}$ & $1000 \mu \mathrm{F}$ \\
\hline
\end{tabular}

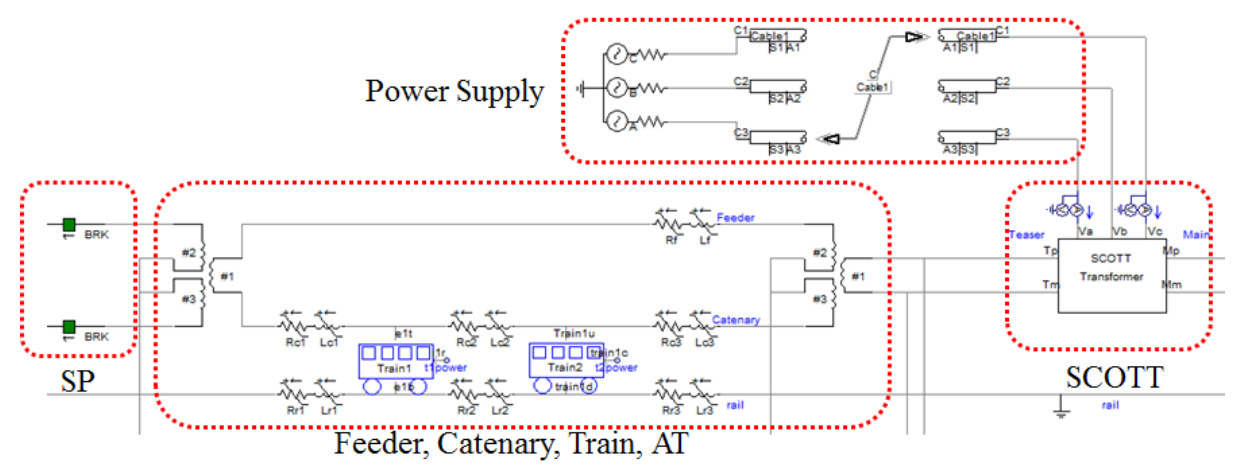

Fig. 13. Conventional electric railway system configuration 


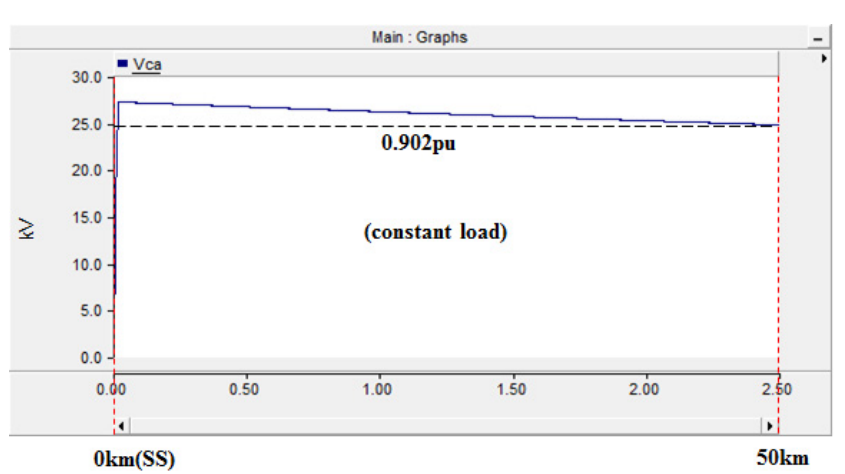

(a) Conventional system

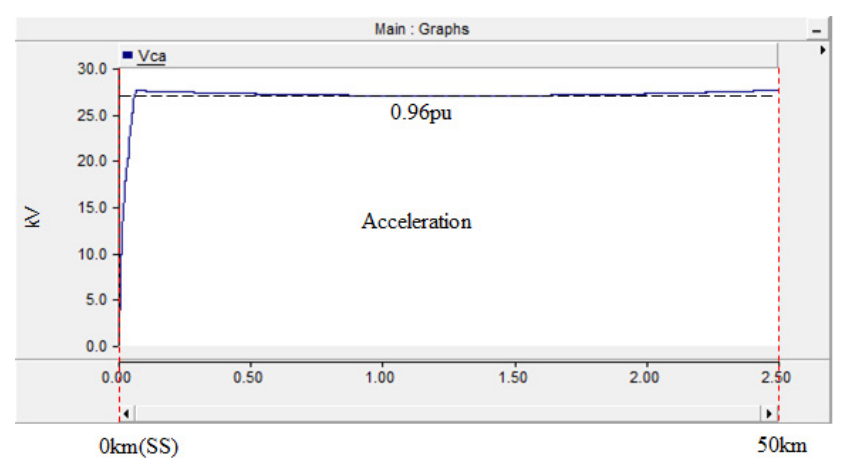

(b) New system

Fig. 14. The catenary voltage (constant rated power)

On the contrary with Fig. 14(a), Fig. 14(b) shows the catenary voltage of novel system, and it can be also observed that the voltage drops to $26.4 \mathrm{kV}$ (only $0.96 \mathrm{pu}$ ) at mid-point of distance between SSs and again it recovers to its rated voltage at the end of catenary since parallel feeding is possible from Active Transformers at both ends of catenary.

At Fig. 9 in the previous section, driving modes according to the speed of train have four sections which are acceleration, coasting, re-acceleration and deceleration. In each section, the power consumption is shown in Fig. 15, where no power consumption at costing and deceleration and in the re-acceleration section, the half of energy is consumed comparing with the initial start-up mode.

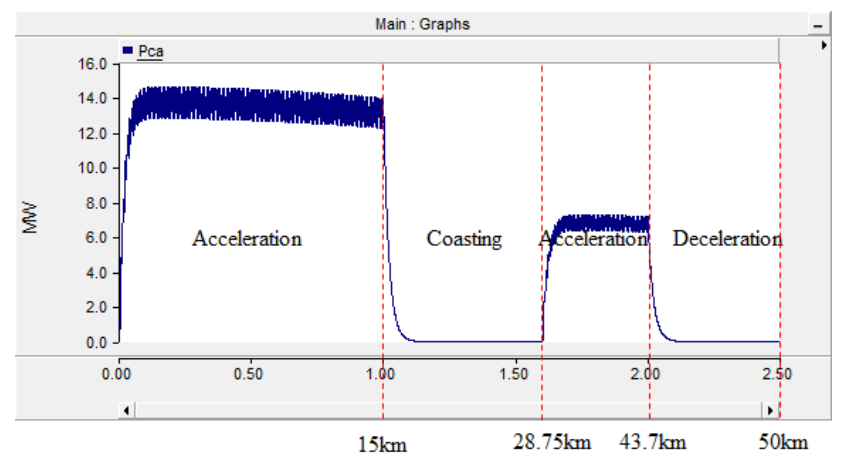

Fig. 15. Power consumption of train

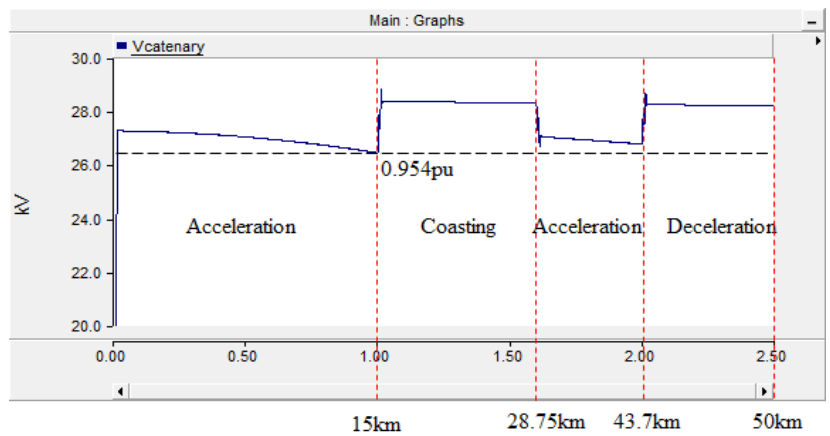

(a) Conventional system

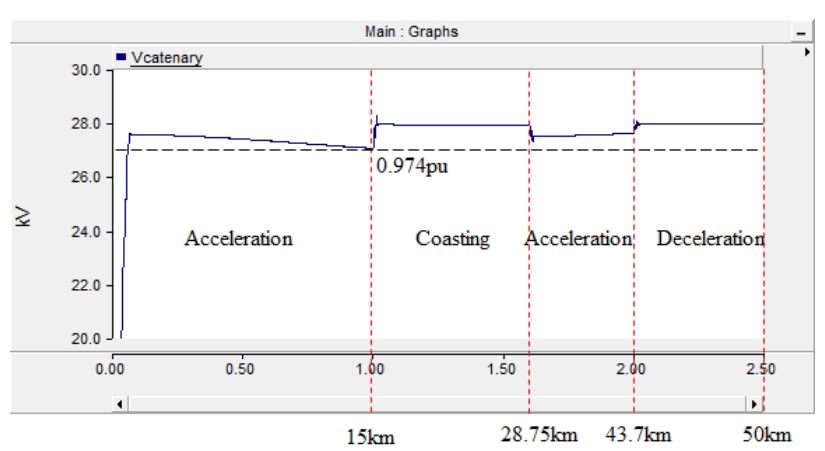

(b) New system

Fig. 16. The catenary voltage of variable load

Fig. 16(a) shows the catenary voltages in four driving modes, and it can be observed that the voltage drop rate in each mode depends on the energy consumption as shown in Fig. 15 and distance from substation as well. There are no voltage drop in the sections of coasting and deceleration because power consumption is zero. For the case of new system as shown in Fig. 16(b), voltage drop rate is improved significantly due to the same reason explained above in the case of constant train load as shown in Fig. 14(b).

\subsection{PCC voltage}

Since input voltage to the train is determined by catenary voltage at train position and affected by the length of catenary, it is concerned about catenary voltage drop as mentioned in previous section. On the other hand, since PCC connects external grid and electric railway system, voltage unbalance due to unbalanced loading at $\mathrm{M}$ and $\mathrm{T}$ phases of SCOTT Transformer results in deteriorated power quality to external grid side. Thus at PCC, it is required to investigate three-phase voltage unbalance, that is, different voltage drop at each phase. Fig. 17 and Fig. 18 show the unbalanced PCC voltages of the conventional system for the cases of constant and variable train loads. In the Fig. 18, the power consumption is zero on the section in $15 \sim 28.75 \mathrm{~km}$ and $43.7 \sim 50 \mathrm{~km}$ because the train is operated by coasting without using electric energy and 


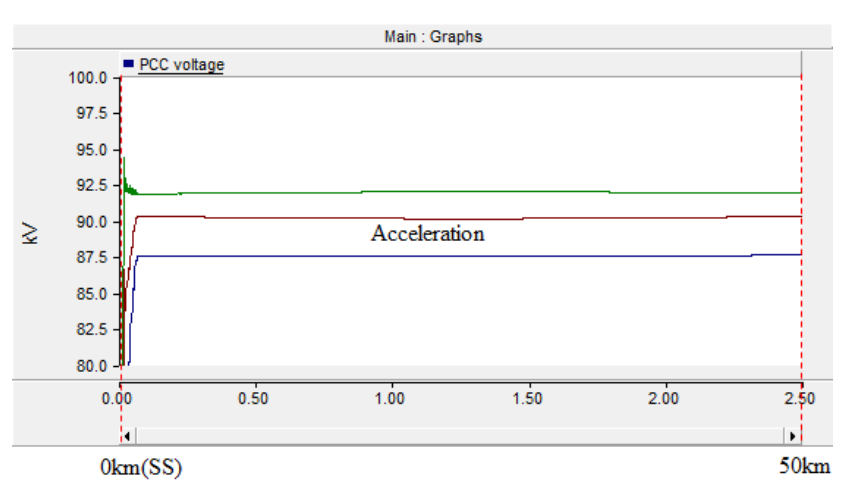

Fig. 17.PCC 3phase voltage of conventional system (constant load)

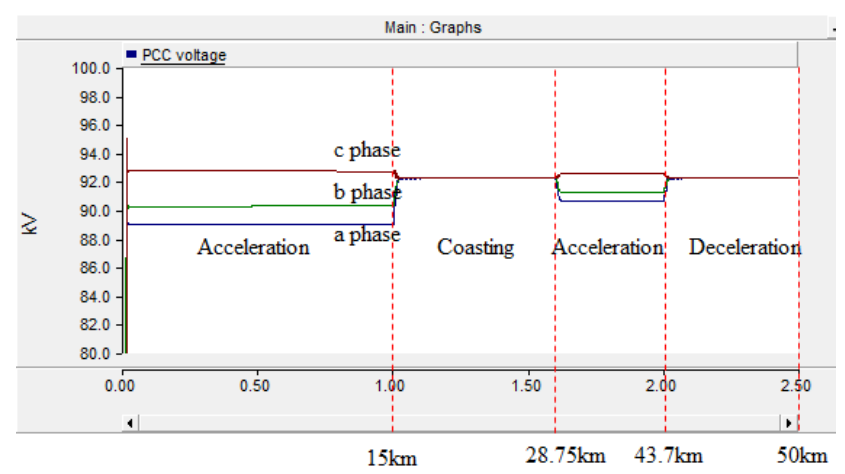

Fig. 18. PCC 3phase voltage of conventional system (variable load)

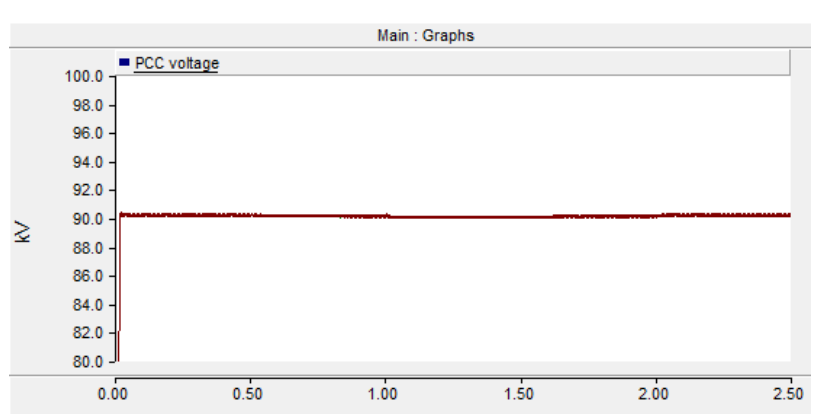

Fig. 19. PCC 3 phase voltage of new system (variable load)

Table 4. Maximum Phase Difference between a, b and c Phases

\begin{tabular}{c|c|c|c}
\hline \multirow{2}{*}{ Section } & \multicolumn{2}{|c|}{ Conventional system } & New system \\
\cline { 2 - 4 } & Constant load & Variable load & Variable load \\
\hline Acceleration & $5.14 \%$ & $4.3 \%$ & insignificant \\
\hline Re-acceleration & $5.18 \%$ & $2.19 \%$ & insignificant \\
\hline
\end{tabular}

braking in each section. Therefore, PCC unbalanced voltages are not caused.

On the other hand as shown in Fig. 19, the Active Transformer does not make any unbalances between phases since it converts to single-phase from three-phase AC instead of $\mathrm{M}$ and $\mathrm{T}$ phases of SCOTT Transformer. The maximum phase differences between $a, b$ and $c$ phases are tabularized in Table 4.

\subsection{Regenerative braking energy}

When decelerating, braking energy is consumed as heat by resistor if there is a dead section between two trains, which is called as generative braking. This braking energy can be returned and supplied to another train nearby without any energy loss, and is called as regenerative braking.

In case of that train 1 and train 2 make an action decelerating and accelerating respectively at the same time in the same section, Fig. 20 shows the total energy consumption for two trains when no regenerative braking for the conventional system. Because of its acceleration, shown the same pattern in section $0 \sim 15 \mathrm{~km}$ on the train 2 meanwhile the train 1 does not generate the power in section $43.7 \sim 50 \mathrm{~km}$. Under the same condition, it is possible to apply regenerative braking in new system, and the energy savings is shown in Fig. 21. In section

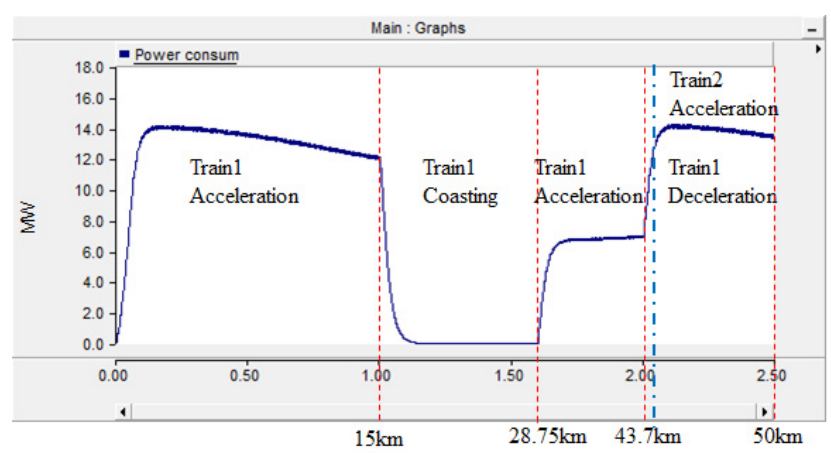

Fig. 20. Energy consumption of conventional system

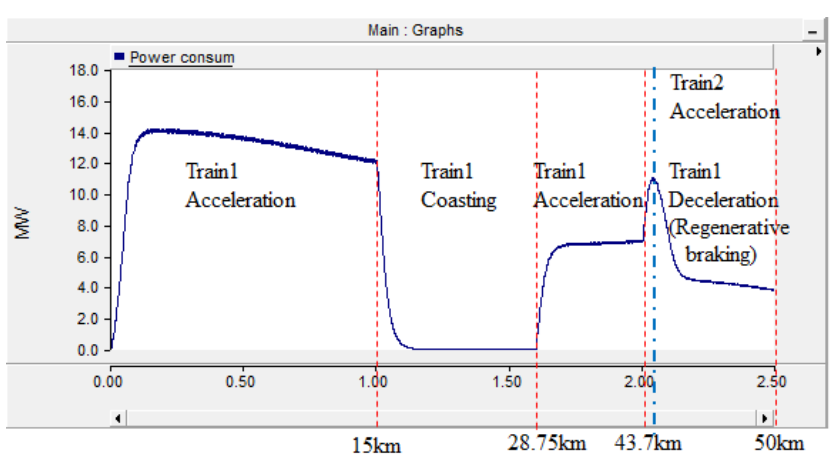

Fig. 21. Energy consumption of new system

Table 5. Power consumption and loss

\begin{tabular}{c|c|c|c|c}
\hline \multirow{2}{*}{ Section } & \multicolumn{2}{|c|}{ Conventional system } & \multicolumn{2}{c}{ New system } \\
\cline { 2 - 5 } & $\begin{array}{c}\text { Consumption } \\
{[\mathrm{kWh}]}\end{array}$ & $\begin{array}{c}\text { Loss } \\
{[\mathrm{kWh}]}\end{array}$ & $\begin{array}{c}\text { Consumption } \\
{[\mathrm{kWh}]}\end{array}$ & $\begin{array}{c}\text { Loss } \\
{[\mathrm{kWh}]}\end{array}$ \\
\hline $0 \sim 15 \mathrm{~km}$ & 1300 & 25.5 & 1300 & 22 \\
\hline $15 \sim 28.75 \mathrm{~km}$ & 0 & 0 & 0 & 0 \\
\hline $28.75 \sim 43.7 \mathrm{~km}$ & 294 & 13.4 & 294 & 5.88 \\
\hline $43.7 \sim 50 \mathrm{~km}$ & 675 & 5.5 & 299 & 0.25 \\
\hline Total & 2269 & 44.4 & 1893 & 28.13 \\
\hline
\end{tabular}


$43.7 \sim 50 \mathrm{~km}$, total $376 \mathrm{kWh}$ is generated and consumed by the train 1 and train 2 , respectively. Therefore, total power consumption in last section is decreased to almost half of conventional system. Details are shown in Table 5.

Table 5 shows the energy consumption and loss for the two cases in each section, and it can be observed that energy is saved as much as $55.7 \%$ in the section of regenerative braking and the total loss is decreased up to $36.6 \%$. In the new system, the power feeding distance is decreased by the parallel feeding. Therefore, due to decreasing impedance of feeding line, total loss is also reduced.

\section{Conclusion}

In this paper, by using the PSCAD / EMTDC, the feeding system of HSR was modeled on the conventional electric feeding system of railway and new system which active transformer is installed. Two systems were simulated with respect to voltage and power loss in the system trains and connection points. Results show that Active Transformer is not only to prevent the voltage unbalance of the system connection points but also reducing the voltage drop across the catenary. Based on these results, it was confirmed that the feeding section can be installed a wider interval than the conventional system. Furthermore, overall energy efficiency is expected to be increased using the regenerative braking energy because of parallel feeding. In conclusion, introduction of Active Transformer would be recommended to improve the performance of railway power feeding system and moreover, it is considered to be compatible to introduce new system in terms of total installation expense.

\section{Acknowledgements}

This research was supported by "Energy saving technology development of urban railroad station" of the Korea Railroad Research Institute, Republic of Korea

\section{References}

[1] M. Fujun, L. An, X. Xianyong, X. Huagen, W. Chuanping, and W. Wen, "A Simplified Power Conditioner Based on Half-Bridge Converter for HighSpeed Railway System," Industrial Electronics, IEEE Transactions on, vol. 60, pp. 728-738, 2013.

[2] H. L. Ginn and C. Guangda, "Flexible Active Compensator Control for Variable Compensation Objectives," Power Electronics, IEEE Transactions on, vol. 23, pp. 2931-2941, 2008.

[3] J. Ma, M. Wu, and S. Yang, "The application of SVC for the power quality control of electric railways," in
Sustainable Power Generation and Supply, 2009. SUPERGEN '09. International Conference on, 2009, pp. 1-4.

[4] T. Pee-Chin, R. E. Morrison, and D. G. Holmes, "Voltage form factor control and reactive power compensation in a $25-\mathrm{kV}$ electrified railway system using a shunt active filter based on voltage detection," Industry Applications, IEEE Transactions on, vol. 39, pp. 575-581, 2003.

[5] T. Pee-Chin, L. Poh Chiang, and D. G. Holmes, "A robust multilevel hybrid compensation system for 25 kV electrified railway applications," Power Electronics, IEEE Transactions on, vol. 19, pp. 1043-1052, 2004.

[6] G. Raimondo, P. Ladoux, A. Lowinsky, H. Caron, and P. Marino, "Reactive power compensation in railways based on AC boost choppers," Electrical Systems in Transportation, IET, vol. 2, pp. 169-177, 2012.

[7] B. Singh, P. Jayaprakash, and D. P. Kothari, "A TConnected Transformer and Three-leg VSC Based DSTATCOM for Power Quality Improvement," Power Electronics, IEEE Transactions on, vol. 23, pp. 27102718, 2008.

[8] Z. Zhiwen, W. Bin, K. Jinsong, and L. Longfu, "A Multi-Purpose Balanced Transformer for Railway Traction Applications," Power Delivery, IEEE Transactions on, vol. 24, pp. 711-718, 2009.

[9] M. Chaves, E. Margato, J. F. Silva, and S. F. Pinto, "New approach in back-to-back m-level diodeclamped multilevel converter modelling and direct current bus voltages balancing," Power Electronics, IET, vol. 3, pp. 578-589, 2010.

[10] R. C. Portillo, M. M. Prats, J. I. Leon, J. A. Sanchez, J. M. Carrasco, E. Galvan, et al., "Modeling Strategy for Back-to-Back Three-Level Converters Applied to High-Power Wind Turbines," Industrial Electronics, IEEE Transactions on, vol. 53, pp. 1483-1491, 2006.

[11] R. Jeevajothi and D. Devaraj, “A New Approach for Constant DC Link Voltage in a Direct Drive Variable Speed Wind Energy Conversion System," Journal of Electrical Engineering \& Technology, vol. 10, pp. 529-538, 32015.

[12] S. Tossaporn and N. Issarachai, "Power System Oscillations Damping by Robust Decentralized DFIG Wind Turbines," Journal of Electrical Engineering \& Technology, vol. 10, pp. 487-495, 32015.

[13] D. Minh-Chau, P. Minwon, K. Gyeong-Hun, and Y. In-Keun, "An Effective Control Scheme of a Backto-Back Converter with Shunt-Connected HTS SMES for Frequency Regulation of an Islanded Microgrid," Journal of Electrical Engineering \& Technology, vol. 9, pp. 1119-1124, 52014.

[14] J. Seungmin, L. Hansang, K. Kisuk, J. Hosung, K. Hyungchul, and J. Gilsoo, "A Study on Peak Power Reduction using Regenerative Energy in Railway Systems through DC Subsystem Interconnection," Journal of Electrical Engineering \& Technology, vol. 
8, pp. 1070-1077, 92013.

[15] L. Shaofeng, P. Weston, S. Hillmansen, H. B. Gooi, and C. Roberts, "Increasing the Regenerative Braking Energy for Railway Vehicles," Intelligent Transportation Systems, IEEE Transactions on, vol. 15, pp. 2506-2515, 2014.

[16] S. Xubin, C. Hu, H. Xiaowei, Z. Mengyang, and D. Hairong, "Regenerative braking energy utilization by multi train cooperation," in Intelligent Transportation Systems (ITSC), 2014 IEEE 17th International Conference on, 2014, pp. 139-144.

[17] L. Seung-Hyuk, O. K. Jin, and J. Hyun-Soo, "Analysis of catenary voltage of an AT-fed AC HSR system," Vehicular Technology, IEEE Transactions on, vol. 53, pp. 1856-1862, 2004.

[18] U. N. Gnanarathna, A. M. Gole, and R. P. Jayasinghe, "Efficient Modeling of Modular Multilevel HVDC Converters (MMC) on Electromagnetic Transient Simulation Programs," Power Delivery, IEEE Transactions on, vol. 26, pp. 316-324, 2011.

[19] X. Jianzhong, Z. Chengyong, L. Wenjing, and G. Chunyi, "Accelerated Model of Modular Multilevel Converters in PSCAD/EMTDC," Power Delivery, IEEE Transactions on, vol. 28, pp. 129-136, 2013.

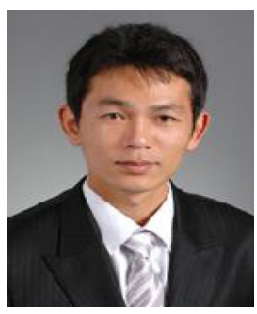

Wook-Won Kim received his B.S., M.S. and Ph. D degree in Electrical Engineering from Hanyang University, Korea, in 2008, 2011 and 2015, respectively. His interests include optimal operation of energy storage system, renewable energy systems and the heuristic algorithm.

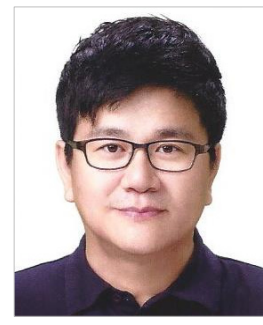

Hyungchul Kim received his BS and MS degree in Electrical Engineering from Korea University, Seoul, Korea in February 1991 and in February 1993 respectively. He then worked for LG electronics Inc. for 6 years. $\mathrm{He}$ received a Ph.D. degree from Texas A\&M University in August 2003. Currently, he is working for Korea Railroad Research Institute. His research area is traction power system and power system reliability.

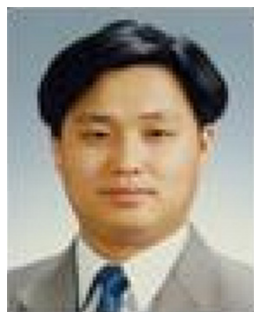

Seung-Kwon Shin received his B.S., M.S. degree in in Electrical Engineering and $\mathrm{Ph}$. D degree in School of Electrical and Computer Engineering from Sungkyun-kwan University, Korea, in 1995, 1998 and 2001, respectively. Currently, he is a Senior Researcher in Korea Railroad Research Institute (KRRI). His research interests include a power electronic control and a railway substation including power quality, measurement and detection.

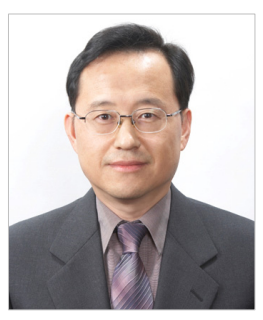

Jin-O Kim received the B.S. and M.S. degrees in electrical engineering from Seoul National University, Seoul, Korea, in 1980 and 1983, respectively, and the Ph.D. degree from Texas A\&M University, College Station, in 1991. Currently, he is a Professor with the Department of Electrical Engineering, Hanyang University, Korea. His interests include power system reliability, planning and power system economics. 